\title{
Do Involvement in Alcoholics Anonymous and Religiousness Both Directly and Indirectly through Meaning in Life Lead to Spiritual Experiences?
}

\author{
Marcin Wnuk (1)
}

check for updates

Citation: Wnuk, Marcin. 2021. Do Involvement in Alcoholics

Anonymous and Religiousness Both Directly and Indirectly through Meaning in Life Lead to Spiritual Experiences? Religions 12: 794. https://doi.org/10.3390/rel12100794

Academic Editors: Bernadette Flanagan and Noelia Molina

Received: 31 July 2021

Accepted: 17 September 2021

Published: 23 September 2021

Publisher's Note: MDPI stays neutral with regard to jurisdictional claims in published maps and institutional affiliations.

Copyright: (C) 2021 by the author. Licensee MDPI, Basel, Switzerland. This article is an open access article distributed under the terms and conditions of the Creative Commons Attribution (CC BY) license (https:// creativecommons.org/licenses/by/ $4.0 /)$
Department of Psychology, Adam Mickiewicz University in Poznań, 60-568 Poznań, Poland; marwnu@amu.edu.pl

\begin{abstract}
Spirituality is a key element of Alcoholics Anonymous (AA) recovery. However, little is known about the potential religious and secular sources of spiritual experiences in AA fellowship. The aim of the study was to verify if in a sample of AA participants, meaning in life mediates the relationship between their religiousness and spiritual experiences, as well as between their involvement in AA and spiritual experiences. The study sample consisted of 70 Polish AA participants, and the following tools were used: the Alcoholics Anonymous Involvement Scale (AAIS); Santa Clara Strength of Religious Faith Questionnaire (SCSORFQ); Purpose in Life Test (PIL); two one-item measures regarding frequency of prayer and Mass attendance; and the Daily Spiritual Experiences Scale (DSES) duration of AA participation, which was positively related to involvement in addiction self-help groups and religiousness. Involvement in AA and religiousness were positively related to meaning in life, which in turn positively correlated with spiritual experiences. This research indicated that in a sample of AA participants, finding meaning in life partially mediates the relationship between religiousness and spiritual experiences, as well as fully mediating the relationship between involvement in AA and spiritual experiences. The theoretical and practical implications are discussed.
\end{abstract}

Keywords: Alcoholics Anonymous; religiousness; involvement in self-help groups; meaning in life; spiritual experiences; mediator variable

\section{Introduction}

According to the literature on alcohol-dependent individuals, involvement in Alcoholics Anonymous (AA) is related to positive outcomes such as sobriety (Zemore 2007; Kaskutas et al. 2003), lower likelihood of relapse (Sheeren 1988), fewer psychiatric severity and depressive symptoms (Galanter et al. 2012), and lower anxiety (Galanter et al. 2012). Recent longitudinal studies have indicated that the AA attendance indirectly, through improving individuals' spirituality, decreased alcohol consumption (usually through sobriety; Kelly et al. 2011; Krentzman et al. 2013; Tonigan et al. 2013; Zemore 2007). Besides involvement in AA, another source of spirituality among AA members is religiousness (Pardini et al. 2000; Lyons et al. 2011; Richard et al. 2000). Despite the fact that they may present religious skepticism, most AA participants identify themselves as spiritual but not religious (McClure and Wilkinson 2020). In comparison to participants of other therapeutic programs for alcohol addiction, AA members also significantly more frequently declare that spirituality is not the same as religiousness (Atkins and Hawdon 2007).

According to Kurtz and White (2015), it is reasonable to distinguish between two groups of participants within AA fellowship: religious spirituality followers and secular spirituality followers. These two groups, which differ in attitude toward spirituality, reflect two different means of spiritual growth in self-help groups, with the first based on religiousness and the second on AA involvement. In the first group, religion can be a framework for having a meaning-oriented system (Silberman 2005), leading to spiritual 
growth. In the second group, the source of a framework for a meaning-oriented system that facilitates spiritual experiences can be the AA philosophy (Alcoholics Anonymous 2001). Little is known about the mechanisms through which involvement in AA and religiousness influence the spiritual experiences of AA participants. In particular, in addiction literature, a lack of precise, well-established definitions for spirituality and religiousness have led to some misunderstandings, as has using them interchangeably (Kelly 2017).

Religiousness and spirituality are separate but overlapping constructs, with spirituality being a broader concept than religiousness (Baumsteiger and Chenneville 2015). Spiritual experiences can be results of both religious practices (King et al. 2020) and some secular activities, such as involvement in AA (Krentzman et al. 2017). Spiritual experiences are conceptualized as a feeling God's presence, feeling deep inner peace or harmony, feeling spiritually touched by the beauty of creation, experiencing a connection to all of life, feeling a selfless caring for others and a desire to be closer to God, or being in union with the divine (Underwood 2011).

The aim of this study was to verify two mechanisms leading to AA participants' spiritual experiences. The first one, called religious spirituality, leads to AA participants' spiritual experiences through facilitating finding meaning in life as a result of religiousness. The second one, secular spirituality, offers AA involvement as an antecedent to finding meaning and purpose in life, which in turn positively correlates with spiritual experiences.

\section{Literature Review}

Both participants who use their own religiousness as a recovery tool and non-religious members who identify themselves as religiously skeptical are involved in AA. The spiritual character of the 12-step program (Kurtz and White 2015; Liisi 1981), a core AA philosophy (Alcoholics Anonymous 2001), has a positive impact on openness to diverse religious affiliations and individuals without religious inclinations. Studies have also proven that the beneficial effect of AA membership is comparable to religion for secular members who define themselves as atheists or agnostic (Tonigan et al. 2002; Winzelberg and Humphreys 1999). Additional research has shown that involvement in AA is positively related to religiousness (Krentzman et al. 2017; Kelly et al. 2011), but some authors have indicated that religious barriers pose difficulties for AA involvement (George and Tucker 1996).

Still, some studies have confirmed that individuals who participate in spiritual and religious activities are more likely to later become affiliated with AA (Kelly and Moos 2003; Emrick et al. 1993). For example, in a study by Krentzman et al. (2017), involvement in AA measured by the Alcoholics Anonymous Involvement Scale positively correlated with private religious practices and positive religious coping. One study of different recovery groups (the 12-step program, Self-Management for Addiction Recovery, Women for Sobriety, and Secular Organizations for Sobriety) also has showed that while the average length of sobriety was similar across groups, spiritual and religious factors were more likely to predict greater program participation among 12-step members than Self-Management for Addiction Recovery or Secular Organizations for Sobriety members (Atkins and Hawdon 2007).

Hypothesis 1 (H1). In a sample of Polish AA participants, AA involvement is positively correlated with religiousness.

AA participation differs from AA involvement, but both of these constructs are positively related (Krentzman et al. 2011). AA attendance is a conditio sine qua non for AA involvement, but it is not an AA involvement indicator because it does not consist of activities being of AA involvement aspects, such as reading of AA literature, being a sponsor, or having a sponsor (Humphreys et al. 1998). It means not necessarily someone who attends AA meetings for a long period of time must engage in sponsorship, considers himself/herself an AA member, or performs service, although most of the AA participants do this. Previous research has highlighted that involvement in AA has changed positively, but these results are limited to a relatively short period of time, no longer than 6 months (Vederhus et al. 2014; Manning et al. 2012). In a study by Tonigan et al. (2017), a higher 
percentage of participants with long AA lifetime histories in comparison with participants with short AA lifetime histories reported higher rates of attending AA, considered themselves AA members, had an AA sponsor, and experienced a spiritual awakening in AA.

Longer AA attendance can lead to growing religious commitment of AA participants. According to research by Tonigan et al. (2017), longer duration of AA participation was related to spiritual/religious practices, such as frequency of prayer, meditation, and thoughts about God, which in turn led to decrease in alcohol consumption and an increase in the percentage of days of abstinence. In another study, positive perceptions of God was related in AA membership (Krentzman et al. 2011).

Hypothesis 2 (H2). In a sample of Polish AA participants, duration of AA participation is positively correlated with involvement in $A A$ and religiousness.

Besides religiousness (Sørensen et al. 2019; Wnuk 2015), among alcohol-dependent individuals, one of the antecedents of meaning in life is involvement in Alcoholics Anonymous (Montgomery et al. 1995; Tonigan 2001; Carroll 1993; Gomes and Hart 2009; Oakes et al. 2000). Involvement in addiction self-help groups facilitates finding meaning in life for substance-addicted individuals (Montgomery et al. 1995; Tonigan 2001; Carroll 1993; Gomes and Hart 2009; Oakes et al. 2000). For example, among participants of Narcotics Anonymous (NA) in the U.S., involvement in NA predicted their level of purpose in life (DeLucia et al. 2016). In a sample of AA participants from Great Britain, the completion of steps 4 and 5 of the 12-step program, as well as involvement in AA, correlated positively with their existential wellbeing (Gomes and Hart 2009). In turn, finding meaning and purpose in life is an important factor for spirituality among individuals diagnosed with addiction. Indeed, many studies have noted the positive relationship between meaning in life and spiritual experiences among alcohol- and drug-addicted patients (Lyons et al. 2011; Webb et al. 2006; Gutierrez 2019). It means that religiousness and involvement in AA can be factors that indirectly through meaning in life positively influence spirituality of AA, with these two aspects of AA functionality serving as a meaning-oriented system (Silberman 2005) that positively affects spiritual experiences.

On the other hand, some studies have indicated a direct positive relationship between AA religiousness (Pardini et al. 2000; Lyons et al. 2011) and spirituality, as well as between involvement in AA and spirituality. For example, Pardini et al. (2000) found that faith leads to higher self-rated spirituality. Lyons et al. (2011) also noted that the religious spiritual practices of drug-addicted individuals predict their spiritual experiences. Moreover, in two studies conducted by Krentzman et al. $(2013,2017)$, involvement in AA predicted spiritual experiences of AA participants.

This means that both religiousness and AA involvement can positively influence AA spiritual experiences, both directly and indirectly through meaning in life.

These four mechanisms were tested.

Hypothesis 3 (H3). In a sample of Polish AA participants, meaning in life mediates the relationship between religiousness and spiritual experiences.

Hypothesis 4 (H4). In a sample of Polish AA participants, meaning in life mediates the relationship between $A A$ involvement and spiritual experiences.

\section{Materials and Methods}

\subsection{Participants}

The participants of this study were 70 individuals addicted to alcohol who attended AA meetings in Poland. The participants orally confirmed their consent to take part in the study, and the data were collected via questionnaire between January and June 2014. The questionnaires were distributed by a psychologist during AA meetings and collected at the next meeting after the participants completed them at home. Of the 200 distributed 
questionnaires, only 70 were returned. This means that the questionnaire return rate was low. This was due to the fact that many participants were absent at the next meeting. Each participant answered "yes" for the question about being diagnosed with alcohol dependence-“"Have you ever been diagnosed with alcohol dependence?".

\subsection{Measures}

\subsubsection{Spiritual Experiences}

The Daily Spiritual Experiences Scale (DSES) consists of 16 questions, each with 6 points ranging from 1 (never or almost never) to 6 (many times daily). The more points scored, the greater the respondent's level of spirituality. Depending on the population, the scale's reliability ranges from $\alpha=0.86$ to 0.95 (Laustalot et al. 2006). The short version of this measure was used for this study, which consists of 6 items.

\subsubsection{Strength of Religious Faith}

The Santa Clara Strength of Religious Faith Questionnaire (SCSORFQ) consists of 10 items that respondents rate on a 5-point Likert scale from 1 (strongly disagree) to 5 (strongly agree). Factor analysis confirmed that the questionnaire items make up one dimension that can be called the strength of religious beliefs (Lewis et al. 2001; Wnuk 2017). The scale's reliability has been determined as $\alpha=0.94-0.96$ (Plante and Boccaccini 1997a, 1997b; Wnuk 2017).

\subsubsection{Involvement in AA}

The Alcoholics Anonymous Involvement Scale (AAIS) was used to assess the participants' lifetime AA attendance (Tonigan et al. 1996). The AAIS consists of 13 items related to AA attendance and involvement in AA activities. For 9 items, participants respond "yes" or "no". For this study, 6 items were chosen that ask if the participants consider themselves a member of AA, go to 90 meetings in 90 days, celebrate AA birthdays, have and/or are a sponsor, and have had a spiritual awakening. For these questions, participants responded "yes" or "no".

\subsubsection{Duration of AA Participation}

For the question regarding duration in AA participation, the participants responded with their corresponding number of months in AA.

\subsubsection{Meaning in Life}

The Purpose in Life Test (PIL) consists of 20 items concerning meaning in life, which subjects respond to by indicating a field on a continuum ranging from 1 to 7 , with 7 representing maximum meaning in life and 1 representing the minimum. The score is computed by adding up the responses to all items. The higher the score, the stronger the satisfaction of the respondent's need for meaning in life; the lower the score, the greater the respondent's existential frustration. This test's reliability, when measured as Pearson's $r$ coefficient, was 0.82 , and when measured with the Spearman-Brown correction, it was 0.90 (Crumbaugh and Maholick 1964).

\subsubsection{Prayer}

The scale for measuring how often the participants prayed consisted of never (1), sometimes (2), once a month (3), once a week (4), and every day (5).

\subsubsection{Mass Attendance}

The participants' Mass attendance was measured on the basis of a 5-point scale consisting of (1) never, with the exception of baptisms, weddings, or funerals; (2) a few times a year; (3) 1-2 times monthly; (4) 2-3 times monthly; and (5) once per week or more. 


\subsection{Statistical Analyses}

All statistical analyses were conducted using IBM SPSS Statistics software (Version 27.0). Structural equation modeling was used to verify the research hypotheses. The structural model was tested by applying path analyses to investigate the relationships among the latent variable of religiousness and the measurable variables, such as AA involvement, meaning in life, duration of AA participation, and spiritual experiences. Religiousness consisted of three indicators: religious faith and two religious practices, such as Mass attendance and prayer. Due to this study's relatively small sample size, the Bollen-Stine bootstrapping method for 5000 samples was used to increase the likelihood of the obtained results' veracity.

The following goodness of fit indicators were used: root mean square error of approximation (RMSEA), the comparative fit index (CFI), goodness of fit index (GFI), and normed fit index (NFI). RMSEA values less than 0.08 , and ideally below 0.05 , indicated an adequate fit to the data (Browne and Cudeck 1993). Values of 0.90 or greater, and ideally above 0.95 , denoted good model fits for the CFI and GFI (Hu and Bentler 1999); in turn, the NFI should exceed 0.90 (Steiger 1990).

\section{Results}

The research variables descriptive statistics are presented in Table 1. R-Pearson correlation coefficients between research variables are presented in Table 2, while the measurement results of the tested model's goodness of fit indicators are shown in Table 3. Final model was presented at Figure 1.

Table 1. Descriptive statistics in Alcoholics Anonymous sample $(n=70)$.

\begin{tabular}{|c|c|c|c|c|c|c|c|}
\hline & $\begin{array}{c}\text { Duration of AA } \\
\text { Participation }\end{array}$ & AAIS & SCSORFQ & $\begin{array}{l}\text { Frequency } \\
\text { of Prayer }\end{array}$ & $\begin{array}{c}\text { Frequency of Mass } \\
\text { Attendance }\end{array}$ & PIL & DSES \\
\hline Mean & 102.76 & 3.77 & 39.84 & 4.18 & 3.41 & 108.14 & 21.37 \\
\hline$S D$ & 71.38 & 1.42 & 10.30 & 1.36 & 1.61 & 14.84 & 7.39 \\
\hline Skewness & 0.73 & -0.53 & -1.38 & -1.24 & -0.35 & -0.88 & 0.76 \\
\hline Kurtosis & 0.09 & 0.47 & -1.45 & -0.18 & -1.59 & 0.96 & 0.03 \\
\hline Minimum & 1 & 0 & 10 & 1 & 1 & 66 & 5 \\
\hline Maximum & 312 & 6 & 50 & 5 & 5 & 134 & 41 \\
\hline Reliability & & 0.68 & 0.95 & - & - & 0.79 & 0.94 \\
\hline
\end{tabular}

(Source: author's research). AAIS-Alcoholics Anonymous Involvement Scale; SCSORFQ—Santa Clara Strength of Religious Faith Questionnaire; PIL-Purpose in Life Test; DSES—Daily Spiritual Experiences Scale.

Table 2. R-Pearson correlation coefficients between research variables $(n=70)$.

\begin{tabular}{|c|c|c|c|c|c|c|}
\hline & 1 & 2 & 3 & 4 & 5 & 6 \\
\hline \multicolumn{7}{|l|}{ 1. Prayer } \\
\hline 2. Mass attendance & $0.61^{* *}$ & & & & & \\
\hline 3. Strength of religious faith & $0.72^{* *}$ & $0.76^{* *}$ & & & & \\
\hline 4. Spiritual experiences & $0.52 * *$ & $0.58^{* *}$ & $0.77^{* *}$ & & & \\
\hline 5. Meaning in life & $0.36^{* *}$ & $0.29 *$ & $0.42^{* *}$ & $0.55^{* *}$ & & \\
\hline 6. Involvement in AA & $0.24^{*}$ & 0.20 & $0.31^{* *}$ & $0.38^{* *}$ & $0.35^{* *}$ & \\
\hline 7. Duration of AA participation & $0.34^{* *}$ & $0.29 *$ & $0.38^{* *}$ & $0.40 * *$ & $0.34^{* *}$ & $0.48^{* *}$ \\
\hline
\end{tabular}


Table 3. Model fit indicators in a sample of Alcoholics Anonymous $(n=70)$.

\begin{tabular}{cccccc}
\hline CMIN/DF & RMSEA & CFI & GFI & NFI & $\begin{array}{c}\text { The Bollen-Stine } \\
\text { Bootstrapping Method }\end{array}$ \\
\hline $0.890(p=0.540)$ & {$[0.00090 \%(0.000 ; 0.058)]$} & 1 & 0.97 & 0.97 & $(p=0.914)$ \\
\hline
\end{tabular}

(Source: author's research).

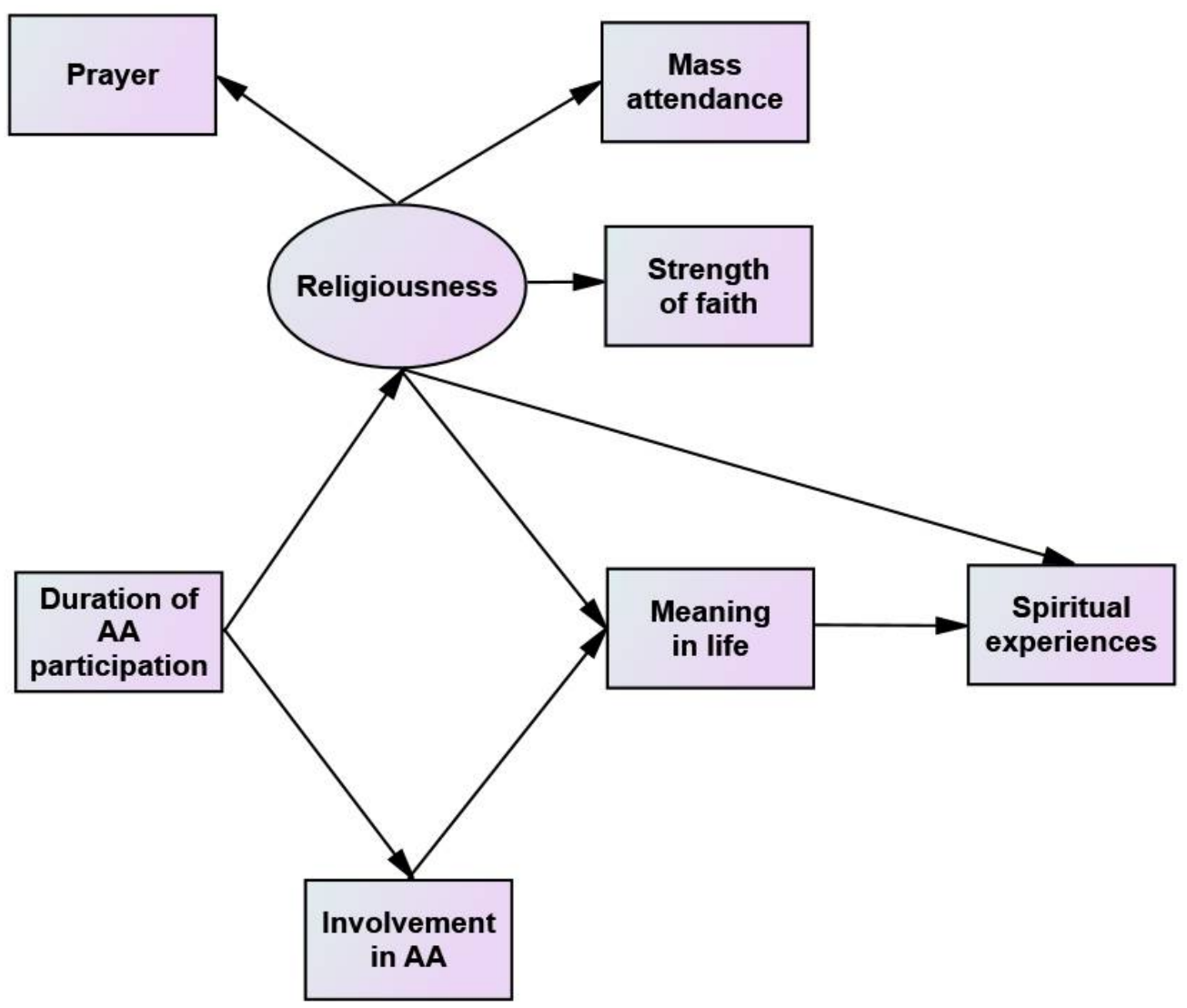

Figure 1. Final model of research. (Source: author's research).

The standardized regression weights for each verified paths, apart of the path between AA involvement and spiritual experiences (CI 95\% [ $-0.122,0.133]$, beta $=0.014 ; p=0.830$ ), were statistically significant. Inconsistent with first hypothesis, the correlation between AA involvement and religiousness (beta $=0.139 ; p=0.247$ ) was not statistically significant. Additionally, the RMSEA value was less than the ideal 0.05 (Browne and Cudeck 1993), although the CFI and GFI values were greater than the anticipated at 0.95 (Hu and Bentler 1999), and the NFI value was greater than 0.90 (Steiger 1990).

Duration of AA participation predicted both AA involvement (CI 95\% [0.264, 0.647], beta $=0.488 ; p<0.01$ ) and religiousness (CI 95\% [0.166, 0.572], beta $=0.391 ; p<0.01$ ), while it indirectly influenced meaning in life (CI 95\% [0.142, 0.373], indirect effect $=0.260$; $p<0.01$ ) and spiritual experiences (CI 95\% [0.157, 0.472], indirect effect $=0.334 ; p<0.01$ ).

Religiousness was both a predictor of meaning in life (CI 95\% [0.131, 0.540], beta $=$ $0.345 ; p<0.01$ ) and spiritual experiences (CI 95\% [0.471, 0.833], beta $=0.677 ; p<0.01)$. In addition, religiousness indirectly influenced spiritual experiences (CI 95\% [0.024, 0.200], indirect effect $=0.091 ; p<0.05)$, as did AA involvement (CI 95\% [0.005, 0.169], indirect effect $=0.068 ; p<0.05$ ).

Meaning in life was also a predictor of spiritual experiences (CI 95\% [0.016, 0.486], beta $=0.265 ; p<0.05)$. 
The tested model explained $42.82 \%$ of the variance in the AA members' spiritual experiences.

Religiousness as a latent variable consisted of three observed religious indicators: strength of religious faith, frequency of prayer, and frequency of Mass attendance. This religiousness indicators were intercorrelated. Both frequency of prayer and frequency of Mass attendance moderately correlated with spiritual experiences. Correlation between religious faith and spiritual experiences was strong, meaning that these were overlapping constructs. From the other side, this correlation was not too strong (less than 0.8) to admit that these are the same constructs or that these are indicators that measure the same construct. Additionally, religiousness as a latent variable was only moderate, not being strong predictor of spiritual experiences, despite the fact that strength of religious faith was the strongest observed indicator of religiousness as a latent variable.

Moreover, differences in relationships between observed religiousness indicators and involvement in AA, as well as religiousness as a latent variable and involvement in AA, were noticed. Frequency of prayer and the strength of religious faith were positively related to involvement in AA, but frequency of Mass attendance was not correlated with involvement in AA. Furthermore, religiousness as a latent variable was not statistically significantly correlated with involvement in AA.

\section{Discussion}

The aim of this study was to explore the potential influence of AA participants' religiousness and AA involvement to find meaning in life as a predictor of their spiritual experiences. In this model, both religiousness and AA involvement served as potential sources of a meaning-making-oriented framework as an element that facilitates spiritual experiences. However, the hypothesis predicting a positive correlation between religiousness and AA involvement was not confirmed because the relationship between the two variables was not statistically significant. These results are not consistent with previous research (Krentzman et al. 2017), indicating religiousness and AA involvement as related variables that are engaged in the spiritual process. This inconsistency can be explained by differences in research samples, distinct socio-cultural contexts, the use of different measures of religiousness, cross-sectional as opposed to longitudinal research design, and the fact that only six items from the original AAIS were used here.

However, the most important factors that determined this difference seemed to be duration of AA participation and abstinence duration, which differed significantly between these studies. It is also possible that in the first stage of the recovery process, involvement in AA is related to religiousness, because of the restoration of this sphere of life that was neglected prior to sobriety. Another important factor that could decide upon the lack of this correlation was religiousness as a latent variable, which consisted of three observed indicators. Two of these indicators, found by R-Pearson coefficient, were positively related to involvement in AA, but one of them was not. It means that frequency of prayer and strength of religious faith were positively correlated with involvement in AA, but frequency of Mass attendance and religiousness as a latent variable were not correlated with involvement in AA. On the other side, it is difficult to predict if in the model, only one indicator of religiousness as an observed variable, such as strength of religious faith or frequency of prayer, would lead to statistically significant correlations between them and involvement in AA. To verify these assumptions, we tested two additional models. The first one was strength of religious faith as an observed variable instead of religiousness as a latent variable, and the second one was frequency of prayer as an observed indicator of religiousness. In both cases, there were no statistically significant correlations between strength of religious faith and involvement in AA, as well as between frequency of prayer and involvement in AA, despite the fact that both of these models were well fitted to the data.

Meanwhile, the hypothesis regarding AA membership as a positive predictor of AA involvement as well as religiousness was confirmed. This means that for alcohol-addicted 
individuals from Poland, longer duration of AA participation is positively related to AA involvement and religious practices, as well as strength of religious faith. These results are consistent with previous research that emphasized that AA participation longer than 6 months is positively related to AA involvement (Vederhus et al. 2014; Manning et al. 2012). As in the study by Krentzman et al. (2011), religiousness was correlated with duration of AA participation. These results have confirmed that AA membership facilitates both AA involvement and religiousness, and these two factors are important elements in the spiritual process based on self-help group participation in Poland.

The hypotheses regarding the mediating role of meaning in life in the relationships between Polish AA participants' involvement in AA or religiousness and spiritual experiences were confirmed, but with one exception. In reference to relationships between religiousness, meaning in life, and spiritual experiences, religiousness predicted spiritual experiences both directly and indirectly through meaning in life. Involvement in AA influenced spiritual experiences only indirectly via meaning in life.

The achieved results were mostly consistent with extant research and have suggested that involvement in self-help groups and religiousness facilitate finding meaning in life for alcohol-addicted individuals (Wnuk 2015; Montgomery et al. 1995; Tonigan 2001; Carroll 1993; Gomes and Hart 2009; Oakes et al. 2000), which in turn leads to more frequent spiritual experiences (Lyons et al. 2011; Webb et al. 2006; Gutierrez 2019). It is worth noting that the direct effect of religiousness as a predictor of spiritual experiences was much greater than its indirect effect. This is attributable to religion and the AA philosophy being two different meaning-oriented systems (Silberman 2003, 2005) that allow alcohol-dependent individuals to improve their spirituality through finding purpose and meaning in life as a result of committing to self-help groups or increasing their faith and religious practices.

These two spiritual mechanisms are thus parallel to and independent of each other.

Following Kurtz and White's (2015) implications, the first mechanism, secular spirituality, has its roots in AA involvement, and the second, religious spirituality, has its source in religious commitment. Both of these mechanisms can be used parallelly with religiously inclined AA participants as well as religiously sceptic AA members. Even religiously skeptical members of AA can restore their religiousness or experience religious conversion because of AA participation.

Longer duration of AA participation is correlated with greater AA involvement and religious commitment. Religion and AA membership both serve alcohol-dependent individuals in participating in self-help groups as frameworks to perceive, experience, and explain life events through the prism of life philosophy. The two frameworks also offer examples from religious and self-help fellowships to model attitudes in the social learning process (Bandura 1986). Ultimately, they allow AA participants to understand the history of their life; facilitate building a new identity; integrate difficult and painful life events; and make life easier as something coherent, predictable, and controllable. Using Frankl's (1992) tragic optimism metaphor, both religious commitment and AA involvement support alcohol-addicted individuals as they transform their tragic and painful situation caused by alcohol dependence into something meaningful. Both religion and the AA philosophy can deliver ultimate life meaning, supporting finding of purpose in life in every situation, especially those most complicated, painful, and difficult to manage (Frankl 1992). Independent of whether religion or AA philosophy lead to AA participants finding meaning in life, the final result of this process is spiritual growth, as reflected in the AA participants' spiritual experiences. Both the secular and religious mechanisms leading to spiritual experiences through finding meaning in life seem to be involved in Neff and MacMaster's (2005) "spiritual transformation". On the basis of social learning (Bandura 1986), the spiritual transformation process includes not only an increased meaning in life, but also, for example, changing perceptions of God, openness to forgiveness, and improved self-acceptance. According to Kurtz and White (2015), AA participants can achieve spiritual growth in two different ways, depending on their attitude towards religion. Notably, non-religious or religiously skeptical AA participants can use secular 
support, such as involvement in AA, on the way to spiritual growth, and still experience similar benefits to the AA religiously inclined members, which can achieve this purpose on the basis of religious commitment (Tonigan et al. 2002; Winzelberg and Humphreys 1999). They can also use religious methods to achieve this goal.

This research yields some theoretical and practical implications. We confirmed two independent spiritual mechanisms based on secular and religious factors (involvement in AA and religiousness) that indirectly led to spiritual experiences among Polish AA participants by increasing meaning in life. Additionally, this study has indicated that these mechanisms are results of AA membership. Longer duration in AA was also related to both more AA involvement and greater religiousness, which in turn indirectly led to the participants' more frequent spiritual experiences through finding meaning in life.

From a practical point of view, practitioners, therapists, and counselors can suggest patients with an alcohol addiction to join AA self-help groups as well as partake in religious practices or develop their faith as a potential way to find meaning in life and thus facilitate spiritual growth. For religiously skeptical individuals, creating therapeutic programs and interventions using elements of the AA philosophy as a probable meaning-oriented system, which can lead to spiritual experiences, may work better. For religiously inclined patients, these therapeutic programs should consist of factors connected to religion and faith as a potential way to improve finding meaning in life and spiritual growth.

\section{Limitations and Future Research}

The conducted research has some limitations. First of all, the generalizability of achieved results is limited only to Roman Catholic AA participants from Poland. The research participants' mean sobriety duration was also relatively long, and the data did not encompass their relapse history and other addictions or diseases that could potentially have influenced their treatment. Additional research is needed to investigate the confirmed model among representatives of other religious denominations, agnostics and atheists, other races, AA members without stable sobriety, and in other cultural contexts.

The sample study was relatively small as well, and the bootstrapping method was used as a good solution in case of normally distributed variables. Using a larger research sample, which would also include alcohol-dependent individuals who recently started their AA participation and do not yet have stable sobriety, is recommended. A larger sample could also permit the verification of, for example, sex and other addictions or diseases as moderators between research variables. Further, it is important to verify whether the presented recovery model could be employed for other self-help groups dedicated to both substance and behavioral addictions, such as drugs, gambling, sex, and work.

One of the measures used, namely, the Alcoholics Anonymous Involvement Scale, had reliability coefficient slightly below the acceptable level, which is 0.7 . This was probably caused by specificity of AA fellowship in Poland and cultural differences. For example, being a sponsor or having a sponsor is not a common phenomenon among Polish AA participants.

From the methodological point of view, it is worth noting that participation in the research was a very selective process because the questionnaire returning rate was low. The conducted study had a cross-sectional, not longitudinal, design. The cross-sectional research model provides the possibility of interpreting the direction of identified relationships between variables, although not from a causation perspective. For more complexity, however, other potential predictors of meaning in life should be incorporated, as should other religious variables (Sørensen et al. 2019) such as religious orientation or religious coping. This research used one latent variable, meaning that the results can only be interpreted as associations, which could differ from connections between observed variables. Finally, future studies could examine strictly observed and not latent variables in order to show the precise relationships between observed variables and verify whether the patterns of associations regarding latent variables are the same.

Funding: This study was funded by author sources. 
Institutional Review Board Statement: Ethical review and approval were waived for this study, due to non-potential harming influence.

Informed Consent Statement: Informed consent was obtained from all subjects involved in the study.

Data Availability Statement: The data presented in this study are available on request from the corresponding author. The data are not publicly available due to privacy of the participants.

Conflicts of Interest: The author declares no conflict of interest.

\section{References}

Alcoholics Anonymous. 2001. Alcoholics Anonymous: The Story of How Many Thousands of Men and Women Have Recovered from Alcoholism, 4th ed. New York: Alcoholics Anonymous World Services.

Atkins, Randolph G., and James E. Hawdon. 2007. Religiosity and participation invmutual-aid support groups for addiction. Journal of Substance Abuse Treatment 33: 321-31. [CrossRef] [PubMed]

Bandura, Albert. 1986. Prentice-Hall Series in Social Learning Theory. Social Foundations of Thought and Action: A Social Cognitive Theory. Englewood Cliffs: Prentice-Hall, Inc.

Baumsteiger, Rachel, and Tiffany Chenneville. 2015. Challenges to the conceptualization and measurement of religiosity and spirituality in mental health research. Journal of Religion and Health 54: 2344-54. [CrossRef]

Browne, Michael W., and Robert Cudeck. 1993. Alternative ways of assessing model fit. In Testing Structural Equation Models. Edited by Kenneth A. Bollen and J. Scott Long. Newbury Park: Sage, pp. 136-62.

Carroll, Stephanie. 1993. Spirituality and purpose in life in alcoholism recovery. Journal of Studies on Alcohol 54: 297-301. [CrossRef] [PubMed]

Crumbaugh, James C., and Leonard T. Maholick. 1964. An experimental study in existentialism: The psychometric approach to Frankl's concept of noogenic neurosis. Journal of Clinical Psychology 20: 200-7. [CrossRef]

DeLucia, Christian, Brandon G. Bergman, Danette Beitra, Hillary L. Howrey, Stephanie Seibert, Amy E. Ellis, and Jessica Mizrachi. 2016. Beyond Abstinence: An examination of psychological well-being in members of Narcotics Anonymous. Journal of Happiness Studies 17: 817-32. [CrossRef]

Emrick, Chad D., J. Scott Tonigan, Henry Montgomery, and Laura Little. 1993. Alcoholics Anonymous: What is currently known? In Research on Alcoholics Anonymous: Opportunities and Alternatives. Edited by Barbara S. McCrady and William R. Miller. Piscataway: Rutgers Center of Alcohol Studies, pp. 41-76.

Frankl, V. Emil. 1992. Man's Search for Meaning: An Introduction to Logotherapy, 4th ed. Translated by I. Lasch. Boston: Beacon Press.

Galanter, Marc, Helen Dermatis, and Courtney Santucci. 2012. Young People in Alcoholics Anonymous: The role of spiritual orientation and AA member affiliation. Journal of Addictive Diseases 31: 173-82. [CrossRef]

George, Anita A., and Jalie A. Tucker. 1996. Help-seeking for alcohol-related problems: Social contexts surrounding entry into alcoholism treatment or Alcoholics Anonymous. Journal of Studies on Alcohol 57: 449-57. [CrossRef]

Gomes, Kevin, and Kenneth E. Hart. 2009. Adherence to recovery practices prescribed by Alcoholics Anonymous: Benefits to sustained abstinence and subjective quality of life. Alcoholism Treatment Quarterly 27: 223-35. [CrossRef]

Gutierrez, Daniel. 2019. Spiritus contra spiritum: Addiction, hope, and the search for meaning. Spirituality in Clinical Practice 6: 229-39. [CrossRef]

Hu, Li-Tze, and Peter M. Bentler. 1999. Cutoff criteria for fit indexes in covariance structure analysis: Conventional criteria versus new alternatives. Structural Equation Modeling 6: 1-55. [CrossRef]

Humphreys, Keith, L. Ann Kaskutas, and Constance Weisner. 1998. The Alcoholics Anonymous Affiliation Scale: Development, reliability, and norms for diverse treated and untreated populations. Alcoholism, Clinical and Experimental Research 22: 974-78. [CrossRef] [PubMed]

Kaskutas, Lee Ann, Norman Turk, Jason Bond, and Constance Weisner. 2003. The role of religion, spirituality and Alcoholics Anonymous in sustained sobriety. Alcoholism Treatment Quarterly 21: 1-16. [CrossRef]

Kelly, John F. 2017. Is Alcoholics Anonymous religious, spiritual, neither? Findings from 25 years of mechanisms of behavior change research. Addiction (Abingdon, England) 112: 929-36. [CrossRef] [PubMed]

Kelly, John F., and Rudolf Moos. 2003. Dropout from 12-step self-help groups: Prevalence, predictors, and counteracting treatment influences. Journal of Substance Abuse Treatment 24: 241-50. [CrossRef]

Kelly, John F., Robert L. Stout, Molly Magill, J. Scott Tonigan, and Maria E. Pagano. 2011. Spirituality in recovery: A lagged mediational analysis of alcoholics anonymous' principal theoretical mechanism of behavior change. Alcoholism, Clinical and Experimental Research 35: 454-63. [CrossRef]

King, Pamela E., Jennifer M. Vaughn, Yeonsoo Yoo, Jonathan M. Tirrell, Elizabeth M. Dowling, Richard M. Lerner, G. J. Geldhof, Jacqueline V. Lerner, Guillermo Iraheta, Kate Williams, and et al. 2020. Exploring religiousness and hope: Examining the roles of spirituality and social connections among salvadoran youth. Religions 11: 75. [CrossRef]

Krentzman, Amy R., Elizabeth Robinson, Brian E. Perron, and James A. Cranford. 2011. Predictors of membership in Alcoholics Anonymous in a sample of successfully remitted alcoholics. Journal of Psychoactive Drugs 43: 20-26. [CrossRef] 
Krentzman, Amy R., James A. Cranford, and Elizabeth Robinson. 2013. Multiple dimensions of spirituality in recovery: A lagged mediational analysis of Alcoholics Anonymous' principal theoretical mechanism of behavior change. Substance Abuse 34: 20-32. [CrossRef]

Krentzman, Amy R., Stephen Strobbe, J. Irene Harris, Jennifer M. Jester, and Elizabeth Robinson. 2017. Decreased drinking and alcoholics anonymous are associated with different dimensions of spirituality. Psychology of Religion and Spirituality 9: S40-S48. [CrossRef]

Kurtz, Ernest, and William L. White. 2015. Recovery Spirituality. Religions 6: 58-81. [CrossRef]

Laustalot, Fleetwood V., Sharon B. Wyatt, Barbara Boss, and Tina McDyess. 2006. Psychometric examination of the Daily Spiritual experiences Scale. Journal of Cultural Diversity 13: 162-67.

Lewis, Christopher Alan, Mark Shevlin, Conor McGuckin, and Marek Navrátil. 2001. The Santa Clara Strength of Religious Faith Questionnaire: Confirmatory Factor Analysis. Pastoral Psychology 49: 379-84. [CrossRef]

Liisi, Sasi K. 1981. Twelve Steps and Twelve Traditions. New York: Alcoholics Anonymous World Services, Inc.

Lyons, Geoffrey C. B., Frank P. Deane, Peter Caputi, and Peter J. Kelly. 2011. Spirituality and the treatment of substance use disorders: An exploration of forgiveness, resentment and purpose in life. Addiction Research E Theory 19: 459-69.

Manning, Victoria, David Best, Nathan Faulkner, Emily Titherington, Alun Morinan, Francis Keaney, Michael Gossop, and John Strang. 2012. Does active referral by a doctor or 12-Step peer improve 12-Step meeting attendance? Results from a pilot randomised control trial. Drug and Alcohol Dependence 126: 131-37. [CrossRef]

McClure, Paul K., and Lindsay R. Wilkinson. 2020. Attending substance abuse groups and identifying as spiritual but not religious. Review of Religious Research 62: 197-218. [CrossRef]

Montgomery, Henry A., William R. Miller, and Scott J. Tonigan. 1995. Does Alcoholics Anonymous involvement predict treatment outcome? Journal of Substance Abuse Treatment 12: 241-46. [CrossRef]

Neff, J. Alan, and Samuel A. MacMaster. 2005. Spiritual mechanisms underlying substance abuse behavior change in faith-based substance abuse treatment. Journal of Social Work Practice in the Addictions 5: 33-54. [CrossRef]

Oakes, K. Elizabeth, John P. Allen, and Joseph W. Ciarrocchi. 2000. Spirituality, religious problem-solving, and sobriety in Alcoholics Anonymous. Alcoholism Treatment Quarterly 18: 37-50. [CrossRef]

Pardini, Dustin A., Thomas G. Plante, Allen Sherman, and Jamie E. Stump. 2000. Religious faith and spirituality in substance abuse recovery. Determining the mental health benefits. Journal of Substance Abuse Treatment 19: 347-54. [CrossRef]

Plante, Thomas G., and Marcus Boccaccini. 1997a. Reliability and validity of the Santa Clara Strength of Religious Faith Questionnaire. Pastoral Psychology 45: 429-37. [CrossRef]

Plante, Thomas G., and Marcus T. Boccaccini. 1997b. The Santa Clara Strength of Religious Faith Questionnaire. Pastoral Psychology 45: 375-87. [CrossRef]

Richard, Alan J., David C. Bell, and Jerry W. Carlson. 2000. Individual religiosity, moral community, and drug user treatment. Journal for the Scientific Study of Religion 39: 240-46. [CrossRef]

Sheeren, Mary. 1988. The relationship between relapse and involvement in alcoholics anonymous. Journal of Studies on Alcohol 49: 104-6. [CrossRef]

Silberman, Israela. 2003. Spiritual role modeling: The teaching of meaning systems: Comment. International Journal for the Psychology of Religion 13: 175-95. [CrossRef]

Silberman, Israela. 2005. Religion as a meaning system: Implications for the new millennium. Journal of Social Issues 61: 641-63. [CrossRef]

Sørensen, Torgeir, Peter la Cour, Lars Johan Danbolt, Hans Stifoss-Hanssen, Lars Lien, Valerie DeMarinis, Heidi Frølund Pedersen, and Tatjana Schnell. 2019. The sources of meaning and meaning in life questionnaire in the Norwegian context: Relations to mental health, quality of life, and self-efficacy. International Journal for the Psychology of Religion 29: 32-45. [CrossRef]

Steiger, James H. 1990. Structural model evaluation and modification: An interval estimation approach. Multivariate Behavioral Research 25: 173-80. [CrossRef]

Tonigan, J. Scott. 2001. Benefits of Alcoholics Anonymous attendance: Replication of findings between clinical research sites in Project MATCH. Alcoholism Treatment Quarterly 19: 67-77. [CrossRef]

Tonigan, J. Scott, Elizabeth A. McCallion, Tessa Frohe, and Matthew R. Pearson. 2017. Lifetime Alcoholics Anonymous attendance as a predictor of spiritual gains in the Relapse Replication and Extension Project (RREP). Psychology of Addictive Behaviors: Journal of the Society of Psychologists in Addictive Behaviors 31: 54-60. [CrossRef]

Tonigan, J. Scott, Gerard J. Connors, and William R. Miller. 1996. Alcoholics Anonymous Involvement (AAI) scale: Reliability and norms. Psychology of Addictive Behaviors 10: 75-80. [CrossRef]

Tonigan, J. Scott, Kristina N. Rynes, and Barbara S. McCrady. 2013. Spirituality as a change mechanism in 12-step programs: A replication, extension, and refinement. Substance Use E Misuse 48: 1161-73.

Tonigan, J. Scott, William R. Miller, and Carol Schermer. 2002. Atheists, agnostics and Alcoholics Anonymous. Journal of Studies on Alcohol 63: 534-41. [CrossRef]

Underwood, G. Lynn. 2011. The Daily Spiritual Experience Scale: Overview and results. Religions 2: 29-50. [CrossRef]

Vederhus, John-Kåre, Christine Timko, Oistein Kristensen, Bente Hjemdahl, and Thomas Clausen. 2014. Motivational intervention to enhance post-detoxification 12-Step group affiliation: A randomized controlled trial. Addiction (Abingdon, England) 109: 766-73. [CrossRef] [PubMed] 
Webb, R. Jon, Elizabeth Robinson, Kirk J. Brower, and Robert A. Zucker. 2006. Forgiveness and alcohol problems among people entering substance abuse treatment. Journal of Addictive Diseases 24: 55-67. [CrossRef] [PubMed]

Winzelberg, Andrew, and Keith Humphreys. 1999. Should patients' religiosity influence clinicians' referral to 12-step self-help groups? Evidence from a study of 3018 male substance abuse patients. Journal of Consulting and Clinical Psychology 67: 790-94. [CrossRef]

Wnuk, Marcin. 2015. Determining the influence religious-spiritual values on levels of hope and the meaning of life in alcohol co-dependent subjects receiving support in self-help groups. Journal of Substance Use 20: 194-99. [CrossRef]

Wnuk, Marcin. 2017. A Psychometric Evaluation of the Santa Clara Strength of Religious Faith Questionnaire among Students from Poland and Chile. Pastoral Psychology 66: 551-62. [CrossRef]

Zemore, Sarah E. 2007. A role for spiritual change in the benefits of 12-step involvement. Alcoholism, Clinical and Experimental Research 31: 76s-79s. [CrossRef] 